\title{
Recikliranje otpadne gume devulkanizacijom
}

\author{
A. Ptiček Siročić, ${ }^{*}$ F. Florijanić, M. Šokman ${ }^{a}$ i D. Dogančića \\ a Sveučilište u Zagrebu, Geotehnički fakultet, Hallerova aleja 7, 42000 Varaždin, Hrvatska \\ ${ }^{b}$ Gumiimpex - GRP d. d., Pavleka Miškine 64c, 42000 Varaždin, Hrvatska
}

Ovo djelo je dano na korištenje pod

\begin{abstract}
Sažetak
Posljednjih nekoliko desetljeća polimeri i polimerni materijali postali su neizostavni dio različitih grana industrije i svakodnevnog života. Zbog vrlo raširene upotrebe elastomera nastaju velike količine gumenog otpada, što je opterećenje za okoliš te zahtijeva posebne mjere zbrinjavanja kako bi se smanjio njihov negativan utjecaj na okoliš. Uzorci polimernih mješavina na bazi prirodnog (NR) i stiren-butadienskog kaučuka (SBR) pripremljeni su u dvije serije s ciljem ispitivanja mehaničkih (prekidna čvrstoća, prekidno istezanje, ispitivanje čvrstoće na zarez) i reoloških svojstava te krajnje upotrebe u proizvodnji gumenih pružnih prijelaza. Prva serija uzoraka pripremljena je s gumenim prahom, a u drugu seriju umiješan je devulkanizirani gumeni prah. Uzorci su miješani na laboratorijskom mikseru te homogenizirani na laboratorijskom dvovaljku, a proces prešanja proveden je na hidrauličkoj preši. Dobiveni rezultati ispitivanja mehaničkih i reoloških svojstava pokazali su da je za NR/SBR polimernu mješavinu koja bi se upotrebljavala za pružne prijelaze znatno bolja opcija dodatak gumenog praha koji je dodatno devulkaniziran.
\end{abstract}

Ključne riječi

Polimeri, guma, recikliranje, otpad, mehanička svojstva, reološka svojstva, devulkanizacija

\section{Uvod}

Polimeri i polimerni materijali zauzeli su nezamjenjivo mjesto $u$ industriji i primjenu u gotovo svim segmentima ljudskog života zahvaljujući velikoj raznolikosti svojstava poput čvrstoće, trajnosti, prilagodljivosti te povoljnoj cijeni. U polimere se ubrajaju i elastomeri (elastomerni materijali, gume) odnosno elastični materijali koji podnose velike deformacije uslijed djelovanja sile, pri čemu ne dolazi do pucanja, nego materijal nakon prestanka djelovanja sile u potpunosti poprima svoj prvobitni oblik. Elastomeri (gume) imaju djelomično (rahlo) umreženu strukturu, što znači da su im makromolekule međusobno povezane i sekundarnim (fizikalnim, međumolekularnim) i primarnim vezama. Netaljivi su, netopljivi, ali bubre. Pod pojmom kaučuk (prirodni ili sintetski) podrazumijeva se neumreženi polimer elastičnih svojstava koji nakon umrežavanja (vulkanizacije) i primješavanja drugih dodataka daje gumu. Proizvodnja guma, ali i njihova potrošnja stvara velike količine gumenog otpada koji iz godine u godinu raste, čime se stvara velik pritisak na okoliš. Europska unija je Direktivom 2008/98/ EC 1 i Direktivom 2018/8512 propisala način gospodarenja otpadom počevši od prevencije, pripreme za ponovnu uporabu, recikliranja te zbrinjavanja. U skladu sa spomenutim direktivama u Hrvatskoj se u sklopu gospodarenja otpadnim gumama otpadne gume recikliraju te se od recikliranog materijala proizvode gumene podloge za dječja igrališta, sportske terene i terase, namještaj, gumene cijevi kao i mnoštvo drugih proizvoda. Recikliranje gume, koje može biti mehaničko i kemijsko, podrazumijeva ponovnu upotrebu gume kao punila prilikom proizvodnje novih gumenih proizvoda ili devulkanizaciju gume odnosno raz-

*Autor za dopisivanje: izv. prof. dr. sc. Anita Ptiček Siročić e-pošta: anita.pticek.sirocic@gfv.hr gradnju gume s ciljem dobivanja novog materijala sličnih svojstava kao kod prvobitnog materijala. Tijekom vulkanizacije gume dolazi do kemijskog povezivanja polimernih lanaca primarnim kemijskim vezama preko čvorova umreženja, kao što su sumporna umreženja, pri čemu nastaje umrežena struktura odgovorna za elastična svojstva gume. S druge strane, tijekom procesa devulkanizacije dolazi do nepotpunog cijepanja lanaca kemijskog umreženja, i stoga takva guma ima različitu molekulsku strukturu u odnosu na nevulkaniziranu gumu, slika 1. Mehanička metoda recikliranja gume, osim ostalog, uključuje i mljevenje gume, pri čemu se dobivena mljevena guma može upotrebljavati kao ojačavalo odnosno punilo u novim proizvodima. ${ }^{3-5}$

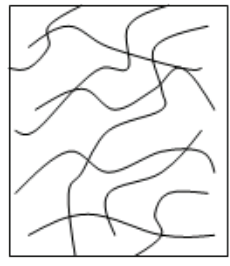

neumrežena guma

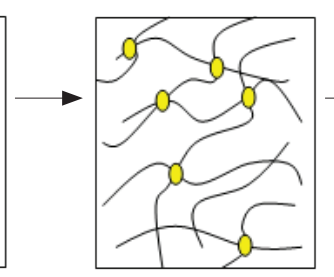

umrežena guma

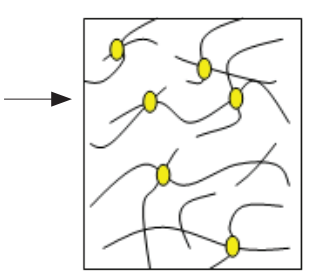

devulkanizirana guma
Slika 1 - Struktura umreženja

Fig. 1 -Crosslinking structure

Proces recikliranja gume ubraja se u djelatnost održivog razvoja s obzirom na to da se od rabljenih guma dobivaju vrijedne sirovine i proizvode novi proizvodi. Gume su otporne na razvoj bakterija i plijesan, toplinu i vlagu, svjetlost, UV zračenje, kao i na razne vrste mineralnih ulja, većinu razrjeđivača, kiselina ili drugih kemikalija. Nadalje, nisu toksične, a njihov oblik, masa i elastičnost čine ih u 
potpunosti upotrebljivima za velik broj različitih proizvoda, u obliku cijelih guma, komada, granulata ili u obliku praha odnosno upotrebljavaju se prilikom izgradnje prometnica, zaštitnih barijera i ograda, umjetnih grebena i mnoštvo drugih primjena. ${ }^{6,7}$ Otpadne auto gume najčešće se recikliraju postupkom mehaničkog usitnjavanja pri čemu se ne stvaraju otpadne supstancije te nema popratnih emisija u okoliš. Cilj ovog rada bio je odrediti optimalni sastav NR/SBR mješavine koja bi se kasnije upotrebljavala za proizvodnju gumenih pružnih prijelaza $\mathrm{i}$ ispitati udjele pojedinih komponenata odnosno gumenog praha i devulkaniziranog gumenog praha kako bi se utvrdio ekološki prihvatljiviji i ekonomski isplativiji sastav mješavine gume.

\section{Eksperimentalni dio}

\subsection{Materijali}

Polimeri upotrijebljeni za pripravu uzoraka su prirodni kaučuk (NR, CV60, Malayan Rubber Inc., Malezija, Mooney viskoznost $60 \mathrm{MU}$, nečistoća 0,02\%), stiren-butadienski kaučuk (SBR, Trinseo 1502, Trinseo Synthetic Rubber, Malezija, Mooney viskoznost 49,7 MU), ojačavalo čađa (CB N550, Omsk Carbon Group, Rusija), cinkov oksid ZnO (Wabco, Poljska), stearinska kiselina (Renacid 444, Renarius), antioksidans (Kumanox 13, Kumho Petrochemical, Južna Koreja) i sumpor (RDC Group, Italija).

\subsection{Priprema uzoraka}

Uzorci polimernih mješavina pripremljeni su u dvije serije. U prvoj seriji uzoraka u mješavinu prirodnog kaučuka (NR) i stiren-butadienskog kaučuka (SBR) umiješan je gumeni prah (GG), dok je u drugu seriju uzoraka umiješan devulkaniziran gumeni prah (GD), slika 2. Gumeni prah dobiven je usitnjavanjem u granulatorima do veličine čestica od 3,0 do $3,5 \mathrm{~mm}$, nakon čega se pomoću rotirajućeg sustava posuda za separaciju dobivaju čestice praha veličine do $0,5 \mathrm{~mm}$.

Uzorci su miješani u laboratorijskom mikseru (Banbury mixer, $3 \mathrm{~L}$, Acten), slika 3a, pri brzini prednjeg rotora od $25 \mathrm{o} \mathrm{min}^{-1}$, stražnjeg rotora od $31 \mathrm{o} \mathrm{min}^{-1}$ i tlaku od 3 bara.

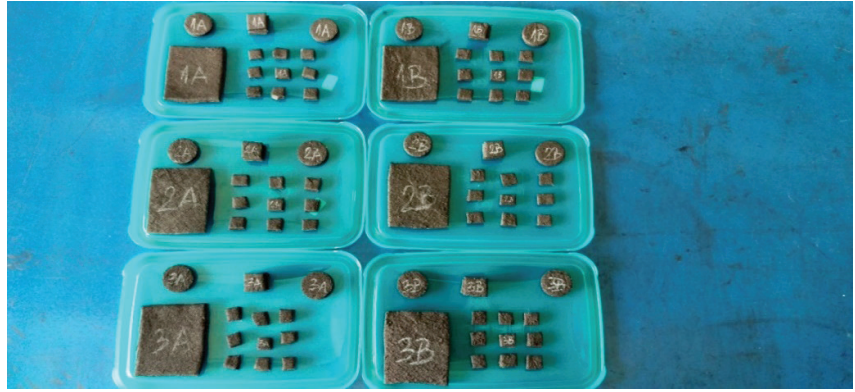

Slika 2 - Uzorci NR/SBR s dodatkom gumenog praha (1A, 2A, $3 \mathrm{~A})$ i dodatkom devulkaniziranog gumenog praha (1B, 2B, 3B)

Fig. 2 - NR/SBR samples with added rubber powder (1A, 2A, $3 \mathrm{~A})$, and with added devulcanized rubber powder (1B, $2 \mathrm{~B}, 3 \mathrm{~B})$

Temperatura na početku miješanja bila je $20^{\circ} \mathrm{C}$, a prilikom ispuštanja smjese $85{ }^{\circ} \mathrm{C}$. Uzorci su zatim homogenizirani na laboratorijskom dvovaljku $(300 \times 150 \mathrm{~mm}$, Collin Lab \& Pilot Solutions), slika $3 \mathrm{~b}$, pri temperaturi od $70{ }^{\circ} \mathrm{C}$. Razmak između valjaka podešen je $1-2 \mathrm{~mm}$, a omjer brzine valjaka $1: 1,13$. Proces prešanja, koji je ujedno i proces vulkanizacije uzoraka, proveden je na hidrauličkoj preši $(400 \times 400 \mathrm{~mm}, 50 \mathrm{t}$, Moore), slika 3c, pri temperaturi od $160{ }^{\circ} \mathrm{C}$ i tlaku od 20 bar u vremenu od $10 \mathrm{~min}$, a sastav ispitivanih uzoraka prikazan je u tablici 1.
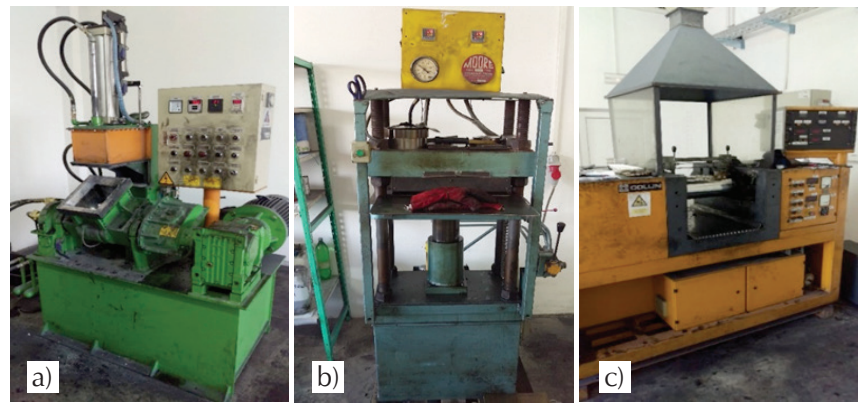

Slika 3 - a) Laboratorijski mikser, b) laboratorijski dvovaljak, c) laboratorijska preša

Fig. 3 - a) Laboratory mixer, b) laboratory two-roll mill, c) laboratory press

Tablica 1 - Sastav pripremljenih uzoraka

Table 1 - Composition of prepared samples

\begin{tabular}{|c|c|c|c|c|c|c|c|c|c|}
\hline $\begin{array}{l}\text { Uzorak } \\
\text { Sample }\end{array}$ & $\begin{array}{c}\text { NR/SBR/ } \\
\text { phr }\end{array}$ & GG/phr & $\begin{array}{l}\text { GD/ } \\
\text { phr }\end{array}$ & $\begin{array}{c}\text { Ulje gumanol } \\
\text { Oil gumanol/phr }\end{array}$ & $\begin{array}{l}\mathrm{ZnO} \\
/ \%\end{array}$ & $\begin{array}{l}\text { Stearinska kiselina } \\
\text { Stearine acid/phr }\end{array}$ & $\begin{array}{l}\text { Sumpor } \\
\text { /phr }\end{array}$ & $\begin{array}{c}\text { Čađa } \\
\text { Carbon black/phr }\end{array}$ & $\begin{array}{c}\text { Antioksidans } \\
\text { Antioxidant/phr }\end{array}$ \\
\hline $1 \mathrm{~A}$ & 100 & 25 & & 5 & 5 & 1 & 2,2 & 65 & 1 \\
\hline $2 \mathrm{~A}$ & 100 & 30 & & 4 & 5 & 1 & 2,2 & 65 & 1 \\
\hline $3 \mathrm{~A}$ & 100 & 35 & & 3 & 5 & 1 & 2,2 & 65 & 1 \\
\hline $1 \mathrm{~B}$ & 100 & & 25 & 5 & 6 & 1,22 & 2,52 & 65 & 1 \\
\hline $2 \mathrm{~B}$ & 100 & & 30 & 4 & 6,2 & 1,27 & 2,59 & 65 & 1 \\
\hline $3 B$ & 100 & & 35 & 3 & 6,4 & 1,32 & 2,65 & 65 & 1 \\
\hline
\end{tabular}

NR - prirodni kaučuk, SBR - stiren-butadienski kaučuk, GG - gumeni prah, GD - devulkanizirani gumeni prah NR - natural rubber, SBR - styrene/butadiene rubber, GG - rubber powder, GD - devulcanized rubber powder 
Za uzorke koji su dodatno devulkanizirani (1B, 2B i 3B) prethodno su provedena reometarska ispitivanja u kojima su umješavani samo devulkanizati bez NR/SBR smjese uz dodatak sumpora, aktivatora $\mathrm{ZnO}$ i stearinske kiseline te ubrzivača s ciljem utvrđivanja devulkanizacije uzoraka. Na temelju tih ispitivanja dobiven je optimalan sastav komponenata.

\subsection{Metode karakterizacije}

\subsubsection{Reološka svojstva}

Pripremljenim uzorcima ispitana su reološka svojstva na reometru (Rheo Check Profile MD, Gibitre Instruments), slika 4a i viskozimetru (Mooney Check Pro, Gibitre Instruments), slika 4b. Reometar se sastoji od dvodijelnog kalupa, gornja ploča kalupa je fiksna, dok se donja ploča kontinuirano zakreće za $0,5^{\circ}$, a temperatura kalupa može se podešavati. Određivanje viskoznosti temelji se na mjerenju zakretnog momenta reznog diska ugrađenog u uzorak, koji se nalazi u zagrijanoj komori mjernog instrumenta. Uzorak se određeno vrijeme izlaže oscilirajućem smičnom naprezanju te se mjeri minimalni i maksimalni otpor zakretanju, vrijeme potrebno da se dosegne $50 \%$ ( $t^{\prime}$ 50) ili $90 \%$ ( $t^{\prime}$ 90) vulkanizacije i vrijeme koje je potrebno da otpor poraste za jednu Mooneyevu jedinicu, MU (Ts 1). Test za određivanje viskoznosti traje 5 min, od čega se uređaj jednu minutu zagrijava do $100{ }^{\circ} \mathrm{C}$, a preostale četiri minute metalni disk se okreće i mjeri otpor rotaciji koja se izražava kao Mooneyjeva viskoznost uzorka.

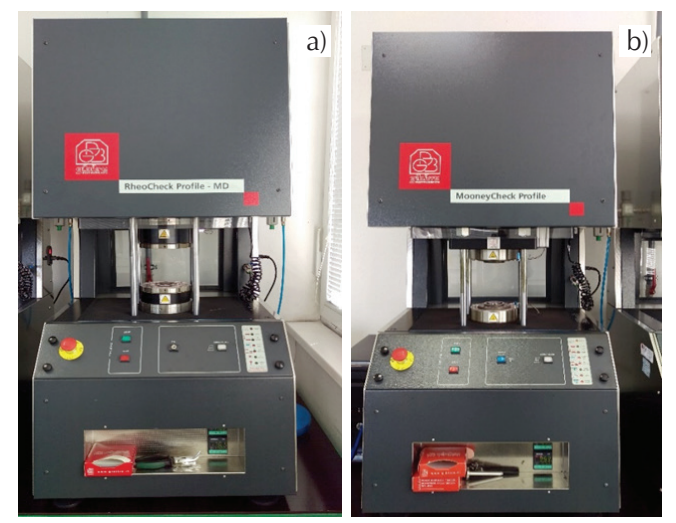

Slika 3 - a) Reometar, b) viskozimetar Fig. 3 - a) Rheometer, b) viscometer

\subsubsection{Mehanička svojstva}

Na uzorcima je provedeno određivanje mehaničkih svojstava pomoću kidalice (Tensor Check Profile, Gibitre Instruments) odnosno prekidna čvrstoća, $\sigma\left(\mathrm{N} \mathrm{mm}^{-2}\right)$, prekidno istezanje, $\varepsilon(\%)$ i ispitivanje čvrstoće sa zarezom (Ts) $\left(\mathrm{N} \mathrm{mm}^{-1}\right)$, slika 5a. Ispitivanje prekidne čvrstoće i prekidnog istezanja provedeno je prema standardu DIN 53504. ${ }^{8}$ Provedeno je i ispitivanje tvrdoće na tvrdomjeru (Shore hardness tester micro, Gibitre Instruments), koji mjeri otpor koji pruža materijal prilikom utiskivanja igle mjernog uređaja u uzorak, slika 5b. Ispitivanje tvrdoće provodi se prema standardu DIN 53505, ${ }^{9}$ a mjerenje je po Shore skali (ShA).
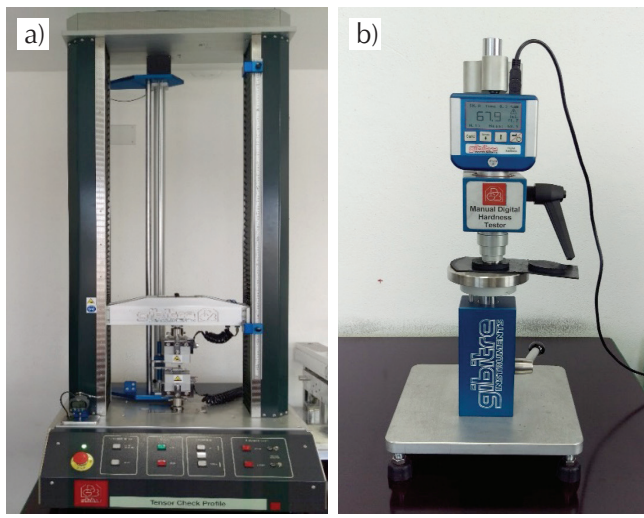

Slika 5 - a) Kidalica, b) tvrdomjer

Fig. 5 - a) Testing machine, b) durometer

Nakon ispitivanja mehaničkih svojstava provedeno je ispitivanje odbojne elastičnosti na uređaju za ispitivanje odbojne elastičnosti (Rebound Tester, Gibitre Instruments), slika 6a. Ispitivanje odbojne elastičnosti omogućava utvrđivanje elastičnosti elastomera s tvrdoćom 30 - 85 točaka po IRHD (International Rubber Hardness Degrees). ${ }^{10}$ Normalizirana elastičnost je odnos između povratne energije i primijenjene energije u sudaru čekića uređaja i uzorka. Mjerenje se izvodi ovisno o kutu odboja čekića nakon udara. Ispitivanje habanja gume provedeno je na uređaju za ispitivanje habanja gume (Gibitre Abrasiometre A, Gibitre Instruments), slika 6b, koji daje procjenu otpornosti uzorka na abraziju prema standardu DIN 53516. ${ }^{11}$ Abrazija na standardnom uzorku dobiva se pomoću standardiziranog brusnog papira na rotirajućem valjku kada uzorak prijeđe duljinu od $40 \mathrm{~m}$.
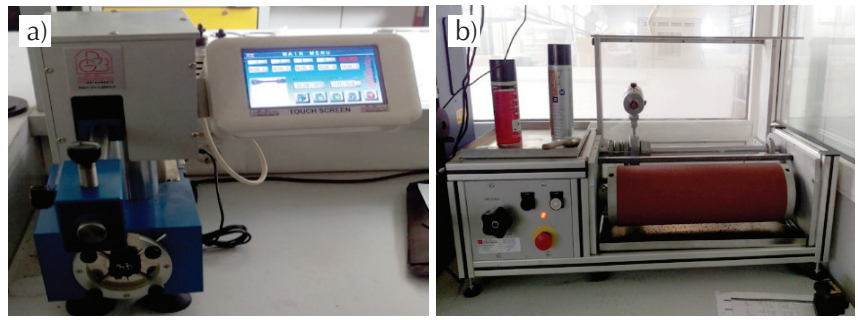

Slika 6 - a) Uređaj za ispitivanje odbojne elastičnosti, b) uređaj za ispitivanje abrazije

Fig. 6 - a) Rebound tester, b) abrasiometer

\section{Rezultati i rasprava}

\subsection{Reološka svojstva}

Reološka svojstva gume odnose se na proučavanje deformacija i tečenja kao posljedice djelovanja vanjskih mehaničkih sila. Proučavanjem reoloških svojstava gume dobiva 
Tablica 2 - Reološka svojstva ispitivanih uzoraka

Table 2 - Rheological properties of samples

\begin{tabular}{|c|c|c|c|c|c|c|}
\hline $\begin{array}{l}\text { Uzorak } \\
\text { Sample }\end{array}$ & $\begin{array}{l}\text { Otpor zakretanja (min) } \\
\text { Minimal torque } / \mathrm{dN} \cdot \mathrm{m}\end{array}$ & $\begin{array}{l}\text { Otpor zakretanja (max) } \\
\text { Maximal torque } / \mathrm{dN} \cdot \mathrm{m}\end{array}$ & $T_{\mathrm{s} 1} / \min$ & $T_{\mathrm{s} 2} / \min$ & $t^{\prime} 50 / \min$ & $t^{\prime} 90 / \min$ \\
\hline $1 \mathrm{~A}$ & 5,33 & 15,02 & 0,61 & 0,91 & 1,48 & 2,85 \\
\hline $2 \mathrm{~A}$ & 5,43 & 12,52 & 0,72 & 1,04 & 1,49 & 2,91 \\
\hline $3 \mathrm{~A}$ & 6,34 & 12,10 & 0,68 & 1,02 & 1,38 & 2,92 \\
\hline $1 \mathrm{~B}$ & 5,07 & 14,07 & 0,74 & 0,90 & 1,28 & 2,61 \\
\hline $2 \mathrm{~B}$ & 5,67 & 13,75 & 0,65 & 0,90 & 1,27 & 2,63 \\
\hline $3 B$ & 6,41 & 14,74 & 0,66 & 0,97 & 1,26 & 2,63 \\
\hline
\end{tabular}

$T_{\mathrm{s} 1}, T_{\mathrm{s} 2}-$ vrijeme potrebno da otpor poraste za $1 \mathrm{MU}$, odnosno $2 \mathrm{MU}$

- time needed for resistance to increase by $1 \mathrm{MU}$ or $2 \mathrm{MU}$

$t^{\prime} 50, t^{\prime} 90$ - vrijeme potrebno za postizanje $50 \%$, odnosno $90 \%$ vulkanizacije

- time needed to reach $50 \%$ or $90 \%$ of vulcanization

se uvid u ponašanje gume odnosno sirove gumene smjese prilikom tečenja u kalupu i uljevnim kanalima. Kako je guma viskoelastičan materijal, koji pokazuje i elastična i viskozna svojstva, rezultati viskoznosti će, uz rezultate tvrdoće, najbolje ukazati na ponašanje uzoraka prilikom prerade. Uzorcima su kao punilo dodani različiti udjeli gumenog praha (GG) te devulkaniziranog gumenog praha (GD) uz ostale aditive kako bi se proveo proces vulkanizacije. Kako bi se utvrdio potreban stupanj umrežavanja NR/SBR mješavina, uzorcima je određen minimalni i maksimalni otpor zakretanju na reometru te vremena potrebna da se vulkanizira $50 \%$ odnosno $90 \%$ mješavine ( $t^{\prime}$ 50, t’ 90), tablica 2. Nadalje, uzorcima je određena Monneyjeva viskoznost, odnosno otpor tečenju, tablica 3 . Iz rezultata je vidljivo (tablica 2) da povećanjem udjela gumenog praha (uzorci 1A, 2A, 3A) dolazi do povećanja minimalnog otpora zakretanja i proporcionalnog smanjenja maksimalnog otpora zakretanja. Može se pretpostaviti da nije došlo do dodatnog umrežavanja tijekom vulkanizacije NR/SBR kaučuka s gumenim prahom s obzirom na to da je gumeni prah već prethodno vulkaniziran. Neznatna odstupanja u vrijednostima brzine vulkanizacije ( $t^{\prime}$ 50, $t^{\prime}$ 90) za uzorke 1A, 2A i 3A ukazuju da različiti udjeli dodanog gumenog praha nemaju značajniji utjecaj na brzinu vulkanizacije pojedinih uzoraka. Međutim, uzorcima kojima je dodan devulkanizirani gumeni prah $(1 \mathrm{~B}, 2 \mathrm{~B}, 3 \mathrm{~B})$ vrijednosti su smanjene u odnosu na uzorke 1A, 1B i 1C s obzirom na to da je vulkanizacija brža zbog prisutnih degradiranih lanaca kaučuka.
Iz tablice 2 vidljivo je slično ponašanje ispitivanih uzoraka NR/SBR gume uz dodatak devulkaniziranog gumenog praha za vrijednosti otpora minimalnog zakretanja, dok vrijednosti otpora maksimalnog zakretanja pokazuju neznatna odstupanja. Rezultati ispitivanja viskoznosti, tablica 3, ukazuju na proporcionalno povećanje vrijednosti početnog otpora zakretanja s povećanjem udjela dodanog gumenog praha u usporedbi s rezultatima uzoraka kojima je dodan devulkaniziran gumeni prah, gdje je vidljivo proporcionalno smanjenje vrijednosti. Povećanjem udjela gumenog praha u smjesi povećava se i viskoznost (63 MU u uzorku 1A s 26,91 \% gumenog praha, a $76 \mathrm{MU}$ u uzorku 3A s $32,92 \%$ gumenog praha). S obzirom na to da je gumeni prah već prethodno vulkaniziran materijal koji u smjesi služi samo kao punilo, može se pretpostaviti da gumeni prah smanjuje mogućnost tečenja i povećava viskoznost. Suprotno tome, u uzorcima kojima je dodan devulkanizirani prah vidljivo je da udio devulkanizata nema prevelik utjecaj na viskoznost s obzirom na to da su vrijednosti gotovo jednake (74 i 75 MU), što se može i očekivati s obzirom na to da se devulkanizirani materijal uvelike ponaša kao i sirova nevulkanizirana smjesa, a ne kao punilo.

\subsection{Mehanička svojstva}

Ispitivanje čvrstoće na zarez, prekidna čvrstoća te prekidno istezanje mehanička su svojstva NR/SBR polimernih mješavina, odnosno parametri koji opisuju ponašanje materijala

Tablica 3 - Mooneyjeva viskoznost ispitivanih uzoraka

Table 3 - Mooney viscosity of samples

\begin{tabular}{c|c|c}
\hline $\begin{array}{c}\text { Uzorak } \\
\text { Sample }\end{array}$ & $\begin{array}{c}\text { Početna Mooneyjeva viskoznost/MU } \\
\text { Initial Mooney viscosity/MU }\end{array}$ & $\begin{array}{c}\text { Minimalna Mooneyjeva viskoznost/MU } \\
\text { Minimal Mooney viscosity/MU }\end{array}$ \\
\hline 1A & 107 & 63 \\
2A & 111 & 69 \\
3A & 120 & 76 \\
1B & 96 & 74 \\
2B & 94 & 75 \\
3B & 93 & 74 \\
\hline
\end{tabular}


pod djelovanjem mehaničke sile i slabljenja materijala prilikom upotrebe. Mehanička svojstva polimernih mješavina koje sadrže različite dodatke ovisit će i o vrsti punila, kompatibilnosti punila s polimerom kao i o veličini te raspodjeli čestica aditiva. ${ }^{12}$ Rezultati ispitivanja mehaničkih svojstava prikazani su u tablici 4.

Iz rezultata mehaničkih svojstava vidljivo je smanjenje prekidne čvrstoće kao i smanjenje prekidnog istezanja s povećanjem dodanog gumenog praha i devulkaniziranog gumenog praha za obje serije ispitivanih uzoraka. Isto ponašanje vidljivo je i za vrijednosti ispitivanja čvrstoće na zarez. Opće je poznato da se dodatkom elastomerne komponente $u$ nemješljive polimerne mješavine smanjuje čvrstoća uzoraka te krajnja svojstva mješavine slabe, što može biti značajno prilikom upotrebe takvih polimernih mješavina. ${ }^{13-15}$ Ukoliko su mješavine mješljive, vrijednosti elastičnosti će se povećati, ali će se vrijednosti prekidne čvrstoće smanjiti. Dodatkom devulkaniziranog gumenog praha u NR/SBR mješavinu vidljiva su manja smanjenja vrijednosti mehaničkih svojstava u odnosu na mehanička svojstva uzoraka s gumenim prahom, tablica 4 . U tablici 5 prikazani su rezultati ispitivanja tvrdoće, odbojne elastičnosti i volumena habanja ispitivanih uzoraka. Dodatkom različitih udjela praha vidljivo je smanjenje vrijednosti tvrdoće za obje serije pripremljenih uzoraka što ukazuje na omekšavanje mješavine budući da se gumeni prah ponaša kao omekšivač. Vrijednosti odbojne elastičnosti za uzorke s gumenim prahom u blagom su porastu, što potvrđuje omekšavanje uzoraka, dok je kod uzoraka kojima je do- dan devulkanizirani prah vidljivo dodatno umrežavanje, što ukazuje na to da prah nije u funkciji punila, već je sastavni dio mješavine. Odbojna elastičnost ne ovisi o udjelu ni o vrsti dodanog punila jer je odbojna elastičnost odraz kompresijskih, tj. tlačnih sila koje su kod elastomera manje podložne utjecaju punila. Otpornost na abraziju izražava se kao gubitak volumena u kubnim milimetrima ili indeks otpornosti na abraziju u postocima. Iz rezultata je vidljivo da su uzorci kojima je dodan gumeni prah (1A, 2A i 3A) neznatno bolje otporni na abraziju u usporedbi s uzorcima kojima je dodan devulkanizirani prah.

\section{Zaključak}

Polimerni otpadni materijali vrijedna su sirovina koja se može materijalno ili energetski oporaviti. Otpadna guma najčešće se reciklira mehaničkim postupkom pri čemu se guma melje i upotrebljava kao punilo kod pripreme novih gumenih proizvoda. Miješanjem različitih vrsta polimernih materijala dobivaju se materijali novih i poboljšanih svojstava u odnosu na polazne komponente, a dodatak elastomerne komponente u polimernu mješavinu može znatno doprinijeti poboljšanju pojedinih svojstava mješavine. Rezultati mehaničkih ispitivanja pokazuju smanjenje prekidne čvrstoće, prekidnog istezanja te čvrstoće na zarez s povećanjem udjela dodanog praha za obje serije uzoraka. Uzorci NR/SBR kojima je dodan gumeni prah koji je dodatno devulkaniziran (1B, 2B i 3B) pokazali su bolja

Tablica 4 - Rezultati ispitivanja mehaničkih svojstava

Table 4 - Results of mechanical properties testing

\begin{tabular}{c|c|c|c}
\hline $\begin{array}{c}\text { Uzorak } \\
\text { Sample }\end{array}$ & $\begin{array}{c}\text { Prekidna čvrstoća } / \mathrm{N} \mathrm{mm}^{-2} \\
\text { Tensile strength } / \mathrm{N} \mathrm{mm}^{-2}\end{array}$ & $\begin{array}{c}\text { Prekidno istezanje } / \% \\
\text { Elongation at break } / \%\end{array}$ & $\begin{array}{c}\text { Čvrstoća na zarez } / \mathrm{N} \mathrm{mm}^{-1} \\
\text { Tear strength } / \mathrm{N} \mathrm{mm}^{-1}\end{array}$ \\
\hline 1A & 4,75 & 205,89 & 36 \\
2A & 3,28 & 137,16 & 32 \\
3A & 2,38 & 130,87 & 31 \\
1B & 6,46 & 270,80 & 39 \\
2B & 5,11 & 240,70 & 38 \\
3B & 5,58 & 166,72 & 36 \\
\hline
\end{tabular}

Tablica 5 - Rezultati ispitivanja mehaničkih svojstava

Table 5 - Results of hardness, rebound elasticity, and abrasion volume testing

\begin{tabular}{|c|c|c|c|}
\hline $\begin{array}{l}\text { Uzorak } \\
\text { Sample }\end{array}$ & $\begin{array}{l}\text { Tvrdoća/ShA } \\
\text { Hardness / ShA }\end{array}$ & $\begin{array}{c}\text { Odbojna elastičnost/\% } \\
\text { Rebound elasticity /\% }\end{array}$ & $\begin{array}{l}\text { Habanje } / \mathrm{mm}^{3} \\
\text { Abrasion } / \mathrm{mm}^{3}\end{array}$ \\
\hline $1 \mathrm{~A}$ & 72 & 28,18 & 172 \\
\hline $2 \mathrm{~A}$ & 67 & 29,23 & 219 \\
\hline $3 \mathrm{~A}$ & 68 & 29,09 & 214 \\
\hline $1 \mathrm{~B}$ & 68 & 28,79 & 239 \\
\hline $2 \mathrm{~B}$ & 60 & 28,43 & 206 \\
\hline $3 B$ & 58 & 28,95 & 265 \\
\hline
\end{tabular}


mehanička i reološka svojstva u odnosu na uzorke 1A, $2 \mathrm{~A}$ i 3A. Povećanjem udjela dodanog gumenog praha dolazi do povećanja minimalnog otpora zakretanja i proporcionalnog smanjenja maksimalnog otpora zakretanja, što ukazuje na to da nije došlo do molekulskog umrežavanja tijekom vulkanizacije NR/SBR kaučuka s gumenim prahom s obzirom na to da je prah već prethodno vulkaniziran. Može se zaključiti da se NR/SBR polimerna mješavina može umješavati s različitim gumenim materijalima, pri čemu se procesom devulkanizacije postižu bolja mehanička i reološka svojstva te se na taj način učinkovito mogu zbrinuti i ukloniti iskorištene gume iz okoliša.

\section{Popis kratica i simbola \\ List of abbreviations and symbols}

\begin{tabular}{|c|c|}
\hline GD & $\begin{array}{l}\text { - devulkanizirani gumeni prah } \\
\text { - devulcanized rubber powder }\end{array}$ \\
\hline GG & $\begin{array}{l}\text { - gumeni prah } \\
\text { - rubber powder }\end{array}$ \\
\hline IRHD & $\begin{array}{l}\text { - međunarodni stupanj tvrdoće gume } \\
\text { - International Rubber Hardness Degrees }\end{array}$ \\
\hline MU & $\begin{array}{l}\text { - Mooneyjeva jedinica } \\
\text { - Mooney unit }\end{array}$ \\
\hline NR & $\begin{array}{l}\text { - prirodni kaučuk } \\
\text { - natural rubber }\end{array}$ \\
\hline SBR & $\begin{array}{l}\text { - stiren /butadienski kaučuk } \\
\text { - styrene/butadiene rubber }\end{array}$ \\
\hline ShA & $\begin{array}{l}\text { - Shore A skala tvrdoće } \\
\text { - Shore A hardness scale }\end{array}$ \\
\hline Ts & 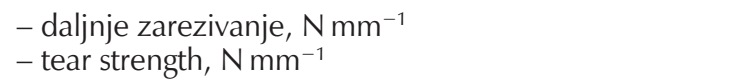 \\
\hline$T_{\mathrm{s} 1}, T_{\mathrm{s} 2}$ & $\begin{array}{l}\text { - vrijeme potrebno da otpor poraste } \\
\text { za } 1 \mathrm{MU} \text {, odnosno } 2 \mathrm{MU} \text {, min } \\
\text { - time needed for resistance to increase } \\
\text { by } 1 \mathrm{MU} \text { or } 2 \mathrm{MU} \text {, min }\end{array}$ \\
\hline $\begin{array}{l}t^{\prime} 50 \\
t^{\prime} 90\end{array}$ & $\begin{array}{l}\text { - vrijeme potrebno da se dosegne } 50 \% \text {, } \\
\text { odnosno } 90 \% \text { vulkanizacije } \\
\text { - time needed to reach } 50 \% \text { or } 90 \% \text { of vulcanization }\end{array}$ \\
\hline UV & $\begin{array}{l}\text { - ultraljubičasto zračenje } \\
\text { - ultraviolet radiation }\end{array}$ \\
\hline$\varepsilon$ & $\begin{array}{l}\text { - prekidno istezanje, } \% \\
\text { - elongation at break, \% }\end{array}$ \\
\hline$\sigma$ & $\begin{array}{l}\text { - prekidna čvrstoća, } \mathrm{N} \mathrm{mm}^{-2} \\
\text { - tensile strength, } \mathrm{N} \mathrm{mm}^{-2}\end{array}$ \\
\hline
\end{tabular}

\section{Literatura \\ References}

1. Directive 2008/98/EC of the European Parliament and of the Council of 19 November 2008 on waste and repealing certain Directives (Text with EEA relevance), https://eur-lex.europa.eu/legal-content/EN/TXT/?uri=celex\%3A32008L0098 (17. 10. 2018.)
2. Directive (EU) 2018/851 of the European Parliament and of the Council of 30 May 2018 amending Directive 2008/98/EC on waste (Text with EEA relevance), https:// eur-lex.europa.eu/legal-content/EN/TXT/?uri=uriserv:OJ.L .2018.150.01.0109.01.ENG (17. 10. 2018.)

3. K. Aoudia, S. Azem, N. A. Hocine, M. Gratton, V. Pettarin, S. Seghar, Recycling of waste tire rubber: Microwave devulcanization and incorporation in a thermoset resin, Waste. Manage. 60 (2017) 471-481, doi: https://doi.org/10.1016/j. wasman.2016.10.051.

4. D. Lo Presti, Recycled Tyre Rubber Modified Bitumens for road asphalt mixtures: A literature review, Constr. Build. Mater. 49 (2013) 863-881, doi: https://doi.org/10.1016/j.conbuildmat.2013.09.007.

5. H. T. Tai Nguyen, T. Nhan Tran, Effects of crumb rubber content and curing time on the properties of asphalt concrete and stone mastic asphalt using dry process, Int. J. Pavement. Res. Technol. 11 (2018) 236-244, doi: https://doi. org/10.1016/j.ijprt.2017.09.014.

6. B. Samarskiy, Analysis of modernization of tire recycling machine for improvement of environmental sustainability and feasibility, Tempere University of Applied Sciences, 2014., https://www.theseus.fi/bitstream/handle/10024/74303/Samarskiy_Boris.pdf?sequence $=1$ (20.10. 2018.)

7. C. E. Caraher Jr., Giant Molecules - Essential Materials for Everyday Living and Problem Solving, John Wiley \& Sons, Canada, 2003., str. 251-274.

8. DIN 535042017 Edition, March 2017 Testing of rubber Determination of tensile strength at break, tensile stress at yield, elongation at break and stress values in a tensile test, https://global.ihs.com/doc_detail.cfm?\&csf=TIA\&document name $=\mathrm{DIN} \% 205350 \overline{4} \&$ item s key $=00028732(17$. 10. $2 \overline{0} 18$.

9. DIN 53505 Shore A and Shore D hardness testing of rubber, https://standards.globalspec.com/std/259165/din-53505 (17. 10. 2018.)

10. General Catalog, Gibitre Instruments, http://pdf.directindustry.com/pdf/gibitre-instruments-srl/general-catalogue/72916-520447.html (17. 10. 2018.)

11. DIN 535161987 Edition, June 1987 Testing of rubber and elastomers; determination of abrasion resistance, https:// global.ihs.com/doc detail.cfm?document name $=$ DIN\%20 53516\&item_s_key=00028739 (20. 10. 2018.)

12. A. Mostafa, A. Abouel-Kasem, M. R. Bayoumi, M. G. El-Sebaie, Rubber-Filler Interactions and Its Effect in Rheological and Mechanical Properties of Filled Compounds, J. Test. Eval. 38 (2010) 1-13.

13. N. Rattanasom, S. Prasertsri, T. Ruangritnumchai, Comparison of the mechanical properties at similar hardness level of natural rubber filled with various reinforcing-fillers, Polym. Test. 28 (2009) 8-12, doi: https://doi.org/10.1016/j. polymertesting.2008.08.004.

14. D. J. Lee, Fracture mechanical model for tensile strength of particle reinforced elastomeric composites, Mech. Mater. 102 (2016) 54-60, doi: https://doi.org/10.1016/j.mechmat.2016.08.008.

15. Y. Qiu, D. Wu, W. Xie, Z. Wang, S. Peng, Thermoplastic polyester elastomer composites containing two types of filler particles with different dimensions: Structure design and mechanical property control, Compos. Struct. 197 (2018) 21-27, doi: https://doi.org/10.1016/j.compstruct.2018.05.035. 


\title{
EXTENDED ABSTRACT
}

\author{
Recycling of Waste Rubber by Devulcanization Process \\ Anita Ptiček Siročić, ${ }^{a^{*}}$ Franjo Florijanić, ${ }^{b}$ Maja Šokman, ${ }^{a}$ and Dragana Dogančića
}

Environmental protection requires constant improvement of quality and the environmental management system in accordance with the international standards and laws in order to reduce human impact on the environment and responsibly manage natural resources. Environmentally acceptable recycling of waste tires and other rubber products is one of the biggest ecological challenges today. Landfilling or dumping of tires causes serious long-term pollution. The lack of alternatives for tire recycling increases their disposal in landfills. Recycling is currently the most effective way to improve the sustainability of the environment. The purpose of this work was to determine the optimal composition of the rubber blend to be used for rubber track crossings production, and to examine the ratio of individual components, i.e., milled recycled tires, and milled and devulcanized tires in order to determine which option is more environmentally friendly and financially viable. In the first series of samples, recycled rubber powder (milled recycled tires) was mixed with a polymer blend of natural rubber and styrene-butadiene rubber, while the second series was milled and the devulcanized tires mixed with natural rubber and styrene-butadiene rubber. Rheological and mechanical properties of all the samples were measured according to appropriate standards. The results showed that an increase in the ratio of rubber powder increased the values of minimal rotation resistance and proportionally reduced the maximum rotation resistance. Minor deviations in the values of the vulcanization rate indicated that various ratios of added rubber powder had no significant effect on the rate of vulcanization of individual samples. The results of the viscosity measurement indicated a proportional increase in the values of initial rotation resistance with the increase in the ratio of added rubber dust compared to the samples prepared with milled and devulcanized rubber, whereby a proportional decrease in value was apparent. From the results of mechanical properties, observed was a reduction in tensile strength and elongation at break values for both series of tested samples. The same behaviour was also observed for the tear strength values. With the addition of different filler ratios, the hardness value for both series of prepared samples had reduced, while the values of the rebound elasticity differed slightly. Significant reduction in hardness value was evident for the samples prepared with the milled and devulcanized rubber powder, which could be attributed to the use of a softener during devulcanization of the material. It can be concluded that NR/SBR polymer blends can be mixed with various recycled rubber materials whereby the devulcanization process enables better mechanical and rheological properties, thus, used rubber tires can be effectively removed from the environment.

\section{Keywords}

Polymers, rubber, recycling, waste, mechanical properties, rheological properties, devulcanization

a University of Zagreb, Faculty of Geotechnical Engineering, Hallerova

aleja 7, 42000 Varaždin, Croatia

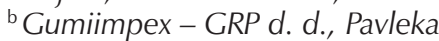

Miškine 64c, 42000 Varaždin, Croatia
Original scientific paper Received November 20, 2018 Accepted February 2, 2019 